Anuario de

Derechos Humanos 2005 


\title{
La Aplicabilidad del Derecho a la Vida al Embrión o Feto en la Jurisprudencia Internacional durante 2004
}

\author{
Patricia Palacios Zuloaga*
}

$U$ no de los temas puestos en el tapete de la jurisprudencia internacional durante 2004 fue la posibilidad de reconocer que la protección brindada por los tratados internacionales de derechos humanos, específicamente en cuanto al derecho a la vida, se extiende a fetos y embriones. No es primera vez que, ante los órganos internacionales encargados de la protección de los derechos humanos, se presentan casos individuales que intentan obtener la tutela del derecho a la vida para no-natos ${ }^{1}$, sin embargo los dos casos emblemáticos del 2004 se diferencian de los anteriores en que ninguno trata específicamente de la interrupción voluntaria del embarazo. Sin embargo, considerando el impacto de un precedente internacional respecto a la protección de la vida antes del nacimiento, ambos fueron vigilados cercanamente por grupos que apoyan o rechazan el derecho de la mujer de practicarse un aborto.

En Vo v. Francia una mujer francesa de origen vietnamita con 20 a 21 semanas de embarazo fue sometida a un aborto terapéutico por razones de salud luego de que, por causa de la acción negligente de un médico, se determinó que su embarazo no podía continuar ${ }^{2}$. La señora Vo estimó que el camino más adecuado para obtener resarcimiento por el daño sufrido era, por medio de la fiscalía francesa, seguir un proceso criminal en contra del médico negligente por cuasidelito de lesiones en su contra y por cuasidelito de homicidio en perjuicio de su hija no-nata ${ }^{3}$. En cuanto al cuasidelito de lesiones, el doctor resultó favorecido por una amnistía ${ }^{4}$. En cambio, la Corte de Casación francesa lo absolvió por el cuasidelito de homicidio razonando que, dado que bajo la legislación francesa no se es persona sino hasta después del nacimiento y dado que las disposiciones del derecho penal se deben interpretar restrictivamente, no se podía calificar la conducta del acusado como cuasidelito de homicidio ${ }^{5}$.

Frente a este resultado, la señora Vo recurrió ante la Corte Europea de Derechos Humanos (en adelante "la Corte" o "la Corte Europea") alegando una supuesta violación del artículo 2 del Convenio Europeo para la Protección de los Derechos y las Libertades Fundamentales (en adelante "Convenio Europeo" ${ }^{6}$. Su petición se basó en que el Estado francés incurrió en responsabilidad internacional bajo dicho instrumento pues la conducta del doctor responsable de la muerte de
* Abogada, Investigadora del Centro de Derechos Humanos, Facultad de Derecho, Universidad de Chile.

1 Por ejemplo, Comisión Interamericana de Derechos Humanos, Baby Boy v. Los Estados Unidos de América. Comisión Europea de Derechos Humanos, Case of Paton v. The United Kingdom, y Case of H. v. Norway.

Corte Europea de

Derechos Humanos, Case of Boso v. Italy.

2 Corte Europea de Derechos Humanos, Case of Vo v. France.

La señora $V_{0}$, quien no dominaba el idioma francés, concurrió a un examen médico prenatal el mismo día que otra señora de nombre parecido que concurrió al hospital para que le removieran un dispositivo intrauterino. El doctor no se cercioró

adecuadamente de la identidad de la señora Vo y procedió a intentar sacar el dispositivo sin percatarse del embarazo avanzado de la peticionaria. Al hacer esto, perforó el saco amniótico de la señora Vo, causando la pérdida de una cantidad

Este comentario, junto con los documentos a que se refiere, están disponibles en formato digital en www.anuariocdh.uchile.cl 
abundante de líquido amniótico. El aborto terapéutico le fue practicado ocho días después.

3 Ibídem, párrafo 13.

4 Ibídem, párrafo 19.

5 Ibídem, párrafo 22.

6 Consejo de Europa, Convenio Europeo para la Protección de los Derechos y las Libertades Fundamentales, 4 de noviembre de 1950.

7 Corte Europea de Derechos Humanos, Case of Vo v. France, párrafo 49

8 Ibídem, párrafo 48, Traducción propia.

9 Ibídem, respecto al Center for Reproductive Rights, pár. 60 a 66; respecto al Family Planning Association, pár. 67 a 73 . Debe decirse que la jurisprudencia de la Corte Europea al referirse específicamente al aborto nunca ha reconocido que los intereses del feto puedan sobreponerse a los derechos de la madre. Véase por ejemplo Boso v. Italia.

10 Ibídem, párrafo 74. El Estado francés dejó en claro su postura al solicitar que la Corte declarara la petición inadmisible ratione materiae debido a que el feto no era titular del derecho a la vida. Ibídem, párrafo 42. su hija no-nata no fue calificada como homicidio culposo y, en consecuencia, el Estado no había cumplido con su obligación de garantizar el derecho a la vida.

El artículo invocado expresa:

\section{Artículo 2. Derecho a la vida}

1. El derecho de toda persona a la vida está protegido por la ley. Nadie podrá ser privado de su vida intencionadamente, salvo en ejecución de una condena que imponga la pena capital dictada por un tribunal al reo de un delito para el que la ley establece esa pena.

2. La muerte no se considerará como infligida en infracción del presente artículo cuando se produzca como consecuencia de un recurso a la fuerza que sea absolutamente necesario:

a. en defensa de una persona contra una agresión ilegítima;

b. para detener a una persona conforme a derecho o para impedir la evasión de un preso o detenido legalmente;

c. para reprimir, de acuerdo con la ley, una revuelta o insurrección.

Al exponer su posición, la peticionaria recordó que la jurisprudencia de la misma Corte Europea establece que en el Estado deben existir disposiciones de derecho penal para efectos de disuadir la comisión de delitos contra la persona ${ }^{7}$.

Por otro lado, a pesar de que, como ya se ha dicho, el caso no trataba específicamente de la interrupción voluntaria del embarazo, las posibles ramificaciones de una sentencia que reconociera que el derecho a la vida existe antes del nacimiento son evidentes. En efecto, la misma señora Vo señaló que "todas las formas de aborto, con la excepción del aborto terapéutico, eran incompatibles con el artículo 2 del Convenio Europeo debido a la interferencia con el derecho a la vida del niño concebido" ${ }^{\prime 8}$. Además, la Corte permitió la intervención como terceros de dos organizaciones no gubernamentales que argumentaron que dicho tribunal no debía entender que el artículo 2 protegía a los no-natos; ambas organizaciones defienden el derecho de la mujer a poner término a su embarazo voluntariamente ${ }^{9}$.

El interés de estas organizaciones se explica por la forma estrecha en que fue planteado el litigio. Pocas personas afirmarían que la conducta del médico en cuestión no afectó los derechos de la señora Vo. Sin embargo, ella no reclamó por la amnistía que benefició al doctor en cuanto a las lesiones que le provocó, sino que planteó el conflicto ante la Corte exclusivamente en torno al supuesto derecho a la vida de su hija no-nata ${ }^{10}$.

La Corte, luego de declarar que la competencia ratione materiae y el disputado agotamiento de los recursos internos estaban tan íntimamente ligados con el litigio planteado que debían ser considerados junto con el fondo del asunto, se abocó, no a responder derechamente la cuestión planteada por la peticionaria sino a 
determinar "si es que es aconsejable que la Corte intervenga en el debate acerca de quién es persona y cuándo comienza la vida"11.

En razón de que este debate no había sido zanjado en la mayoría de los Estados partes y que no existía consenso en Europa con respecto al comienzo a la vida, la Corte concluyó que la definición de dicho momento cae dentro del margen de apreciación del Estado ${ }^{12}$. Posteriormente afirmó que:

“... la Corte está convencida que, tal como están las cosas, no resulta deseable ni posible siquiera responder de manera abstracta la pregunta de si el niño no-nato es persona para efectos del artículo 2 del Convenio ("personne" en el texto francés). En el presente caso considera innecesario examinar si es que el término repentino del embarazo de la postulante cae dentro de la esfera del artículo 2 dado que, aun si la disposición fuera aplicable, el Estado parte cumplió con las exigencias relativas a la preservación de la vida en el ámbito de la salud pública"1"13.

La Corte respaldó lo anterior con la afirmación de que la vida del feto estaba íntimamente ligada con la de su madre y que, por ende, pudo ser protegida a través de ella, en especial ya que no existía conflicto entre los derechos de la madre, el padre y la hija no-nata ${ }^{14}$. Además, afirmó que en casos de muerte no intencional no se requiere de recursos criminales en todos los casos, pudiendo bastar recursos civiles o disciplinarios ${ }^{15}$.

En base a estas consideraciones, la Corte resolvió, por 14 votos contra 3 que los hechos no constituían una violación del artículo 2 del Convenio Europeo por parte del Estado francés.

Uno podría pensar que esta sentencia dejó insatisfechos tanto a aquellos que afirman la legalidad de que las mujeres opten por terminar sus embarazos voluntariamente como a aquellos que la rechazan. Por un lado, la Corte se negó a afirmar categóricamente que el feto era sujeto autónomo del derecho a la vida, pero por otro, declaró en forma unánime que la demanda de la señora Vo era admisible bajo el artículo 2 , rechazando la excepción de incompetencia ratione materiae interpuesta por el Estado, de esta manera aceptando tácitamente que podría haber una violación del derecho a la vida del feto, aun si en el presente caso no se configuró ${ }^{16}$. En suma, no hay un precedente claro que se pueda usar para apoyar una pretensión futura que trate sobre la vida intrauterina, cualquiera que sea la posición del autor.

El segundo caso que ha atraído la atención de grupos de ambos lados del debate sobre la legalidad del aborto voluntario se sitúa en el sistema interamericano de derechos humanos y a la fecha de la publicación de este trabajo, continúa pendiente su trámite ante la Comisión Interamericana de Derechos Humanos (en adelante "la Comisión").

Se trata de Ana Victoria Sánchez Villalobos y Otros contra Costa Rica, petición que fue declarada admisible por la Comisión en marzo de 2004.

Los peticionarios son pacientes de médicos y establecimientos dedicados a la fecundación in vitro que alegan variadas violaciones a
11 Ibídem, párrafo 81, traducción propia.

12 Ibídem, párrafo 82. Harris, O'Boyle y Warbrick describen esta herramienta de la siguiente manera: "En términos generales, significa que se permite al Estado cierta medida de discreción, sujeta a supervisión europea, al tomar acciones legislativas, administrativas $y$ judiciales en el campo de los derechos de la Convención". Harris, D.J, O'Boyle, M. y Warbrick, C. Law of the European Convention on Human Rights, ed. Butterworths, Londres, 1995.

Traducción propia.

La doctrina del margen de apreciación es muy propia de la Corte Europea y se puede observar en varias de sus sentencias, por ejemplo Case of Handyside $v$ The United Kingdom.

13 Ibídem, párrafo 85, traducción propia.

14 Ibídem, párrafo 86.

15 Ibídem, párrafo 90.

16 Ahora bien, la reticencia de la Corte para pronunciarse sobre la extensión temporal del derecho a la vida fue cuestionada por el Juez Costa en su opinión individual anexada a la sentencia. En ella el Juez afirma:

“¿Por qué la Corte no debería hacerse cargo de los conceptos 'toda persona' y 'derecho a la vida' (que el Convenio Europeo sobre Derechos Humanos no define) de la misma manera que lo ha hecho desde sus inicios con los conceptos 'derechos y obligaciones civiles', 'cargos criminales' y 'tribunales'...?" Ibídem, Opinión Separada del 
Juez Costa párrafo 7. Traducción propia.

El Juez Costa postuló además que reconocer que fetos y embriones tienen derecho a la vida no necesariamente implicaría que este derecho es absoluto y por ende no acarrearía necesariamente la invalidación de legislación que permitiera la terminación voluntaria del embarazo.

${ }^{17}$ Comisión Interamericana de Derechos Humanos, Ana Victoria Sánchez Villalobos y Otros contra Costa Rica,

Admisibilidad.

La parte peticionaria alega violaciones por parte del Estado de Costa Rica de los artículos 1, 2, 4, 5, 8, 11(2), 17, 24, 25, 26 y 32 de la Convención Americana sobre Derechos Humanos, artículos 3, 10 y 15 del Protocolo de San Salvador, y artículos 1 y 7 de la Convención de Belém do Pará.

18 Sala Constitucional de la Corte Suprema de Justicia, Exp: 95-0017340007-CO, Res: 200002306.

19 Ibídem, Considerando III.

20 Ibídem, Considerando IX.

21 Organización de Estados Americanos, Convención Americana sobre Derechos Humanos, 22 de noviembre de 1969 .

22 Para un resumen de la historia fidedigna de la inclusión de esta frase en el artículo véase Medina Cecilia, La Convención Americana sobre Derechos Humanos Teoría y Jurisprudencia. Vida, integridad personal, libertad personal, debido proceso y recurso judicial, texto en imprenta, 2005. sus derechos humanos ${ }^{17}$ basadas en la determinación por parte de la Sala Constitucional de la Corte Suprema de Justicia costarricense de que el decreto aprobatorio del Reglamento para las Técnicas de Reproducción Asistida que incluye la llamada Fecundación In Vitro adolecía de inconstitucionalidad ${ }^{18}$. De acuerdo con la sentencia de dicho tribunal, la inconstitucionalidad de la cual adolecía el decreto era de forma y de fondo: aquélla se fundamenta en el principio de reserva legal ${ }^{19}$ mientras que ésta se basa en que la técnica de fecundación in vitro y transferencia embrionaria atenta contra la vida humana ${ }^{20}$.

Para fundamentar esta afirmación, el tribunal nacional hizo referencia a varias disposiciones de derecho internacional de los derechos humanos que consagran el derecho a la vida e hizo hincapié especial en el artículo 4.1 de la Convención Americana sobre Derechos Humanos (en adelante "la Convención Americana") ${ }^{21}$ que establece:

\section{Artículo 4. Derecho a la Vida}

Toda persona tiene derecho a que se respete su vida. Este derecho estará protegido por la ley y, en general, a partir del momento de la concepción. Nadie puede ser privado de la vida arbitrariamente.

Como es evidente, la gran diferencia entre esta disposición y aquella consagrada en el Convenio Europeo es la obligación impuesta a los Estados Americanos a proteger la vida "en general, a partir del momento de la concepción" ${ }^{22}$. En opinión de la mayoría de la sala, la posibilidad de eliminación o destrucción de óvulos fecundados durante el proceso de fecundación in vitro implica una violación del derecho a la vida protegido bajo el referido artículo 4.1. En efecto, según la sentencia:

"La objeción principal de la Sala es que la aplicación de la técnica importa una elevada pérdida de embriones, que no puede justificarse en el hecho de que el objetivo de ésta es lograr un ser humano, dotar de un hijo a una pareja que de otra forma no podría tenerlo. Lo esencial es que los embriones cuya vida se procura primero y luego se frustra son seres humanos y el ordenamiento constitucional no admite ninguna distinción entre ellos"123.

En términos prácticos, la sentencia de la Sala Constitucional terminó por prohibir la práctica de la fecundación in vitro, dejando a los peticionarios sin la posibilidad de recurrir a esta forma de reproducción asistida dentro de Costa Rica.

La Comisión Interamericana de Derechos Humanos declaró admisible la petición de los pacientes en cuanto se refiere a los artículos 1 (obligación de respetar los derechos), 2 (deber de adoptar disposiciones de derecho interno), 11 (protección de la honra y de la dignidad), 17 (protección de la familia) y 24 (igualdad ante la ley) de la Convención Americana sobre Derechos Humanos. Ahora bien, y tomando en cuenta el camino seguido por la Corte Europea en Vo, surge de inmediato la siguiente interrogante: para efectos de determinar si es 
que el actuar del Estado se ajustó o no a las exigencias de la Convención Americana, ¿la Comisión tendrá que pronunciarse sobre la interpretación que la Sala Constitucional hizo del artículo 4.1 de ese tratado? Dicho de otro modo, ¿será necesario que la Comisión determine la compatibilidad de la fecundación in vitro con el derecho a la vida tal como está consagrado en el artículo 4.1 de la Convención Americana?

En caso afirmativo se puede pensar que, dada la redacción particular del artículo 4.1, la discusión no se centrará en cuándo comienza la vida (la Convención Americana obliga al Estado a protegerla a partir de la concepción) sino más bien se centrará en cómo se protege la vida, concretamente si óvulos fecundados son "concebidos" y, más importante, qué se debe entender por las palabras "en general". La Comisión se ha referido a este último punto con anterioridad, en el caso Baby Boy v. Los Estados Unidos de América, cuando el artículo fue invocado en apoyo a una pretensión anti-abortista. En dicha oportunidad la Comisión estableció que:

"A la luz de los antecedentes expuestos, queda en claro que la interpretación que adjudican los peticionarios de la definición del derecho a la vida formulada por la Convención Americana es incorrecta. La adición de la frase "en general, desde el momento de la concepción" no significa que quienes formularon la Convención tuviesen la intención de modificar el concepto de derecho a la vida que prevaleció en Bogotá, cuando aprobaron la Declaración Americana. Las implicaciones jurídicas de la cláusula "en general, desde el momento de la concepción" son substancialmente diferentes de las de la cláusula más corta "desde el momento de la concepción", que aparece repetida muchas veces en el documento de los peticionarios" ${ }^{\prime 24}$.

Como ya se ha dicho, a la fecha de esta publicación, el caso se encuentra pendiente ante la Comisión. Tendremos que esperar, entonces, para ver si es que el debate sobre la legalidad del aborto en nuestro continente va a verse modificado por la resolución de un caso que no dice directa relación con él, o si por el contrario, y como ocurrió en Europa, se mantendrá en los términos actuales.

\section{Jurisprudencia Internacional Citada}

\section{Comisión Europea de Derechos Humanos}

Case of Paton v. The United Kingdom, Application No 8416/78, sentencia del 13 de mayo de 1980.

Case of H. v. Norway, Application № 17004/90, decisión sobre admisibilidad, 19 de mayo de 1992.

\section{Corte Europea de Derechos Humanos}

Case of Handyside v The United Kingdom, Application No 5493/72, sentencia del 4 de noviembre de 1976.
${ }^{23}$ Sala Constitucional de la Corte Suprema de Justicia, op. cit. nota 18, considerando IX.

${ }^{24}$ Comisión Interamericana de Derechos Humanos, Baby Boy v. Los Estados Unidos de América, párrafo 30 . 
Case of Boso v. Italy, Application No 50490/99, sentencia del 5 de septiembre de 2002.

Case of Vo v. France, Application No. 53924/00, sentencia del 8 de Julio de 2004.

\section{Comisión Interamericana de Derechos Humanos}

Baby Boy v. Los Estados Unidos de América, Caso 2141, Resolución 23/81, Informe del 6 de marzo de 1981

Ana Victoria Sánchez Villalobos y Otros contra Costa Rica, Petición 12.361, Admisibilidad, Informe № 25/04, 11 de marzo de 2004.

\section{Normativa Internacional}

\section{Consejo de Europa}

Convenio Europeo para la Protección de los Derechos y las Libertades Fundamentales, 4 de noviembre de 1950. Publicado por la Secretaría del Tribunal Europeo de Derechos Humanos, en http:// www.echr.coe.int/Convention/webConvenESP.pdf actualizado a noviembre de 1998, consultado el 7 de marzo de 2005.

\section{Organización de Estados Americanos}

Convención Americana sobre Derechos Humanos, 22 de noviembre de 1969. Publicada por la Comisión Interamericana de Derechos Humanos en http://www.cidh.org/Basicos/Basicos2.htm, consultado el 31 de marzo de 2005.

Protocolo Adicional a la Convención Americana sobre Derechos Humanos en Materia de Derechos Económicos, Sociales y Culturales, "Protocolo De San Salvador", 17 de noviembre de 1988. Publicado por la Comisión Interamericana de Derechos Humanos en http:// www.cidh.org/Basicos/Basicos4.htm, consultado el 31 de marzo de 2005.

Convención Interamericana para Prevenir, Sancionar y Erradicar la Violencia Contra la Mujer "Convención De Belém Do Pará", 9 de junio de 1994. Publicada por la Comisión Interamericana de Derechos Humanos en http://www.cidh.org/Basicos/Basicos8.htm, consultado el 31 de marzo de 2005. 